secretarial help and Dr Barbara Hull-Drysdale. Mrs Mei Hoh, and Mrs Francine Laurent for technical help.

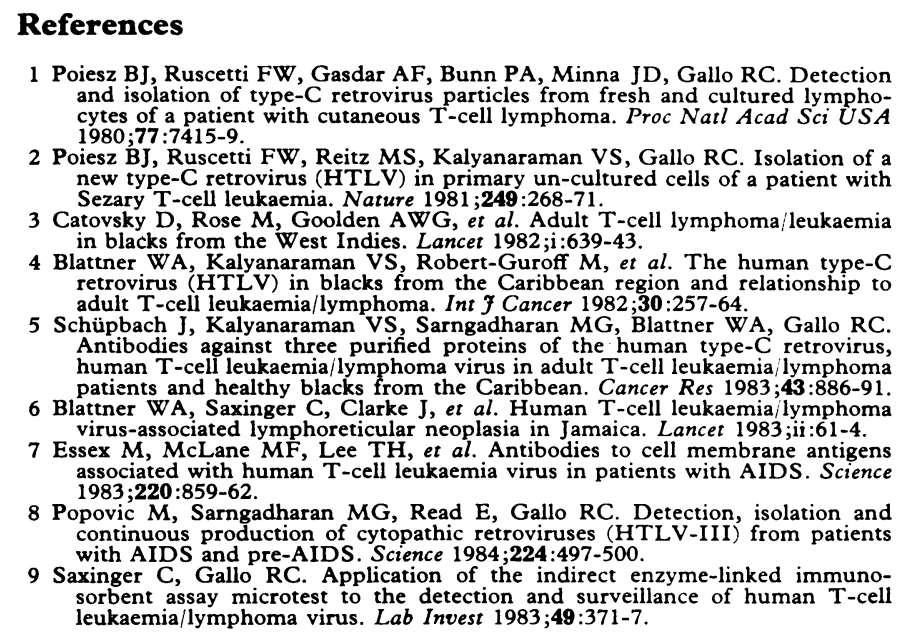

10 Saxinger C, Blattner WA, Levine T, et al. HTLV-I antibodies in Africa. Science $1984 ; 225: 1473-6$

11 Towbin H, Staehelin T, Gordon J. Electrophoretic transfer of proteins from polyacrylamide gels to nitrocellulose sheets : procedure and some applications.

12 Sarngadharan MG, Popovic M, Bruch L, Schüpbach J, Gallo RC. Antibodies eactive with a human T lymphotropic retrovirus (HTLV-III) from patients
with AIDS. Science 1984;224:506-8.

13 Takatsuki K, Uchiyama J, Sagawa K, Yodoi J. Adult T-cell leukaemia in Japan. In: Seno $S$, Takaku $F$, Irino $S$, eds. Topics in haematology. Amsterdam: Excerpta Medica, 1977:73-7.

14 Blattner WA, Blayney DW, Robert-Guroff M, et al. Epidemiology of human T-cell leukaemia/lymphoma virus. F Infect Dis 1983;147:406-16.

15 Gessain A, Gouannelle A, Escarmant O, Calendar A, Schaffar-DesHayes L, De-The G. HTLV antibodies in patients with non-Hodgkin lymphomas in Martinique. Lancet $1984 ; \mathrm{i}: 1183-4$.

16 Flemming AF, Yamamoto N, Bhusnurmath SR, Maharajan M, Schneider J, Hunsmann G. Antibodies to ATLV(HTLV) in Nigerian blood donors and 17 patients with chronic lymphatic leukaemia or lymphoma. Lancet 1983 ;ii:34-5 associated lymphoproliferative disease : report of two cases in Nigeria. Br Med 1984;288:1495-6.

18 Kalyanaraman VS, Sarngadharan MG, Bunn PA, Minna JA, Gallo RC. Antibodies in human sera reactive against internal structural protein of human
T-cell lymphoma virus. Nature $1981 ; 294: 271-3$.

19 Sodroski JG, Rosen CA, Haseltine WA. Trans-acting transcriptional activation of the long terminal repeat of human $T$ lymphotropic viruses in infected cells Science $1984 ; 255: 381-5$.

20 Gallo RC, Sliski A, Wong-Staal F. Origin of human T-cell leukaemia/lymphoma virus. Lancet $1983,11: 962$

C, Patrick A, Penco F, Jankey N. Aids in Trinidad. Lancet $1984 ; \mathrm{i}: 103$.

22 Bartholomew C, Raju C, Jankey N. The acquired immune deficiency syndrome in Trinidad; a report of two cases. West Indian Med $\mathcal{F} 1983 ; 32: 177-80$.

(Accepted 20 December 1984)

\title{
Controlled study of withdrawal symptoms and rebound anxiety after six week course of diazepam for generalised anxiety
}

\author{
K G POWER, D W A JERROM, R J SIMPSON, M MITCHELL
}

\begin{abstract}
A group of patients suffering from anxiety, as assessed by general practitioners and psychologists using research criteria for generalised anxiety, were treated with either diazepam or placebo double blind for six weeks. This active treatment period was preceded by a one week single blind placebo "wash in" period and followed by a two week single blind placebo "wash out" period. The results suggest that diazepam can produce rebound anxiety and withdrawal symptoms when used in moderate doses and for what has previously been regarded as a safe length of time. If replicated these results have implications for the therapeutic use of benzodiazepines.
\end{abstract}

\section{Introduction}

Benzodiazepines are among the most commonly prescribed drugs in the Western world. Each year about $14^{\circ}{ }_{0}$ of adults in the

Department of Psychology, University of Stirling, Stirling FK9 4LA K G POWER, MA, MAPPSCI, senior clinical research psychologist

D W A JERROM, sSC, MPHIL, principal clinical psychologist and honorary lecturer

Health Centre, Bridge of Allan, FK9 4EU

R J SIMPSON, CHB, MRCPSYCH, general practitioner

Astra Clinical Research Unit, Edinburgh EH1 3EP

M MITCHELL, PHD, clinical scientist

Correspondence to: Mr K G Power.
United Kingdom take a benzodiazepine as an anxiolytic or hypnotic. ${ }^{1}$

In 1977 diazepam was the drug most commonly prescribed by general practitioners, accounting for $4.3 \%$ of all prescriptions. ${ }^{2}$ These figures reflect the tendency for most anxiety disorders to be treated in primary care, less than $10 \%$ being referred to psychiatrists. ${ }^{3}$ Few studies assessing the efficacy of benzodiazepines, however, are carried out in a primary care setting; most are carried out with psychiatric outpatients. ${ }^{4}$

Despite the widespread use of benzodiazepines persistent criticisms have been raised about the lack of efficacy after prolonged use, ${ }^{5-7}$ "rebound" anxiety, ${ }^{8}$ and the emergence of withdrawal symptoms at the end of treatment. ${ }^{9-11}$ Studies of the withdrawal of benzodiazepine after the administration of recommended short term therapeutic doses have been few. ${ }^{6}{ }^{12}$ In many cases high doses of benzodiazepines have been used ${ }^{13-15}$ or patients have been maintained within recommended doses for prolonged periods (one to 16 years) before withdrawal of the drug. ${ }^{16-18}$

Our study compared the effectiveness of diazepam versus placebo in the management of generalised anxiety over a six week double blind period in a primary care setting. Withdrawal reactions from diazepam were investigated during a two week withdrawal period, when single blind placebo was substituted for the double blind active treatment. The effect of placebo on the state of anxiety at initial presentation was assessed during one week's single blind treatment with placebo before the double blind treatment was started.

\section{Patients and methods}

Patients were initially screened for psychological and physical morbidity by their general practitioner and were told the nature of the 
trial. A clinical psychologist (KGP) then assessed their characteristics, present state, and severity of illness. Patients were considered for the study if they had a primary diagnosis of generalised anxiety according to present state examination ${ }^{19}$ and research diagnostic criteria ${ }^{20}$; a minimum score of 15 obtained on the Hamilton rating scale for anxiety ${ }^{21}$; symptoms that had lasted for at least one month; no continuous and prolonged use of benzodiazepine in the past 12 months; not taken psychotropic drugs at the time of initial assessment or in the past three weeks; and given written consent.

Twenty six patients presenting to general practitioners with a suspected generalised anxiety state who were thought suitable for pharmacological treatment were referred for inclusion in the study. Three patients were not included as their state of anxiety was not severe enough to meet the entry criteria. One patient was withdrawn from the study after the use of non-prescribed benzodiazepine, and one further patient withdrew before the double blind treatment was started. Twenty one patients were included in the study.

All patients were initially given single blind placebo three times daily for a "wash in" period of at least a week before treatment was started. Thereafter they were randomly allocated to either $5 \mathrm{mg}$ diazepam three times daily or placebo three times daily double blind for six weeks. Finally, they were given single blind placebo for a further two weeks. All drugs were dispensed in identical capsules packaged in Dosettes, which were returned at each assessment to check compliance.

The Kellner and Sheffield self rating scale of distress, ${ }^{22}$ designed to measure changes in symptoms of neurotic patients participating in therapeutic trials, was completed at the general practitioner's initial assessment before the placebo wash in period began. Thereafter the Kellner and Sheffield scale and the Hamilton rating scale for anxiety ${ }^{2}$ were administered by an independent psychologist assessor on day 0 that is, at the end of the placebo wash in period but immediately before the start of the active treatment period-and on days 7,14 , 28 , and 42 of the six week double blind active treatment period. A final assessment was conducted at the end of the two week withdrawal period (day 56).

Adverse reactions to the drug regimen were recorded at each assessment by means of an open ended interview and check list of adverse symptoms.

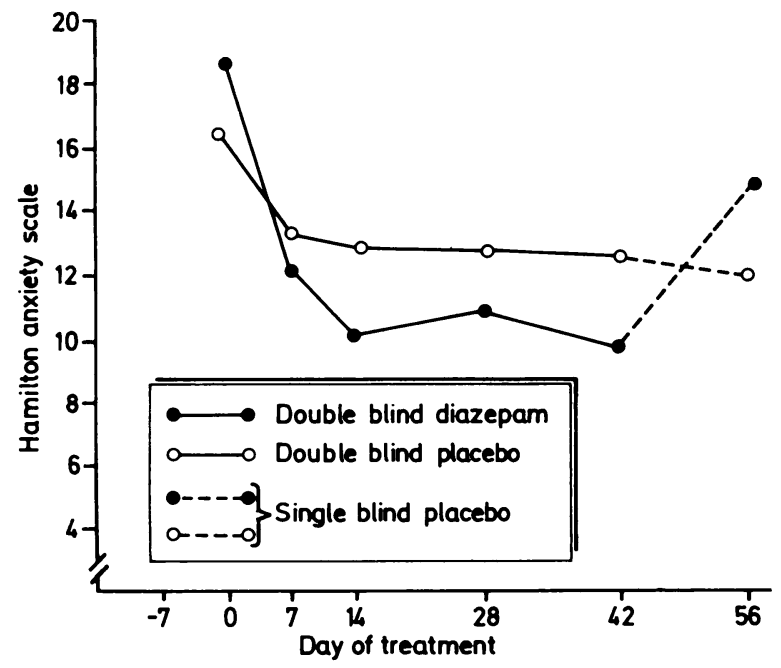

FIG 1-Effects of diazepam and placebo on Hamilton anxiety ratings.

\section{Results}

The main demographic details of patients included in the study are presented in table I. Figure 1 shows the mean results for patients taking diazepam or placebo on the Hamilton rating scale for anxiety (days $7,14,28$, and 42 ) and at the end of the withdrawal period (day 56). Figure 2 shows the mean results for both groups on the Kellner and Sheffield ratings, according to the same time schedule as above and also before the start of the wash in period.

No significant difference in mean scores was seen between patients taking diazepam and those taking placebo on the initial Hamilton rating scale (day 0$)(t=1 \cdot 23, \mathrm{df}=19)$ and initial Kellner and Sheffield rating scale (day -7$)(t=0.0623, \mathrm{df}=19)$. Effects of treatment for both groups were analysed by computing within group $t$ tests and one way repeated measures of variance.
In the repeated measures analysis of variance ${ }^{23}$ a between group factor (drug treatment) and a within groups factor (time of assessment) were included to assess the relative effect on anxiety scores of diazepam and placebo over time.

TABLE I-Demographic features of patients treated with diazepam and placebo

\begin{tabular}{lcc}
\hline & \multicolumn{2}{c}{ Treatment } \\
\cline { 2 - 3 } & Diazepam $(\mathrm{n}=10)$ & Placebo $(\mathrm{n}=11)$ \\
\hline Mean age (years) & $31 \cdot 8$ & $36 \cdot 9$ \\
Sex & $2 \mathrm{M}, 8 \mathrm{~F}$ & $1 \mathrm{M}, 10 \mathrm{~F}$ \\
Duration of symptoms (months) & $4 \cdot 9$ & $3 \cdot 2$ \\
No with history of anxiety & 6 & 10 \\
No previously prescribed benzodiazepine & 7 & 7
\end{tabular}

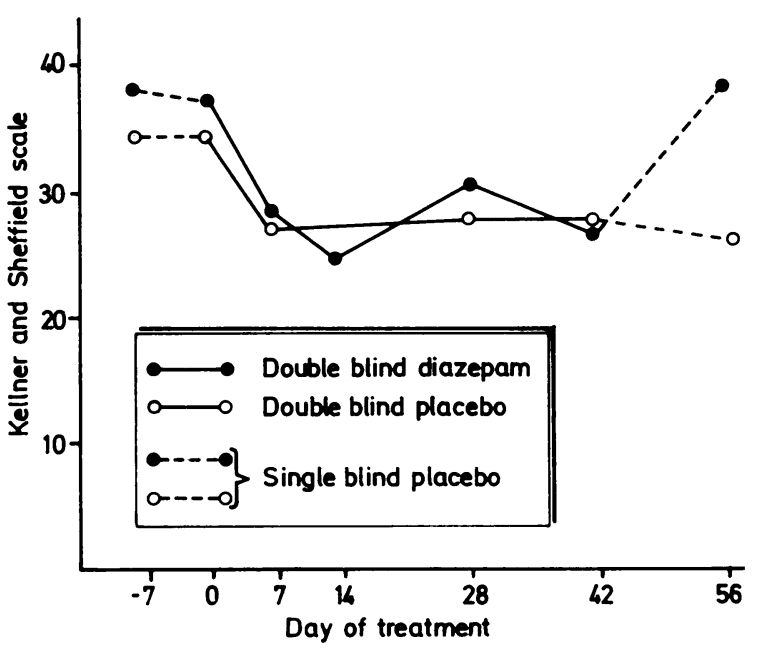

FIG 2-Effects of diazepam and placebo on Kellner and Sheffield ratings.

\section{HAMILTON RATING SCALE FOR ANXIETY}

Within group $t$ tests comparing Hamilton rating scale scores before and during "active" treatment suggested that both diazepam ( $t=$ $4.90, \mathrm{df}=9, \mathrm{p}<0.001)$ and to a less extent placebo $(t=2.47, \mathrm{df}=10$, $p<0.05)$ significantly reduced anxiety ratings.

A repeated measures analysis of variance with drug (diazepam $v$ placebo) and time of assessment (before and during active treatment) as the main factors failed to find any significant differences between drug groups but did show a significant reduction in anxiety for both groups over time $(\mathrm{F}=16.32, \mathrm{df}=4, \mathrm{p}<0.001)$ with no drug $\times$ time of assessment interaction effect.

Within group $t$ tests comparing Hamilton rating scale scores during and after active treatment showed a significant increase in scores for the diazepam group $(t=2.49, \mathrm{df}=9, \mathrm{p}<0.05)$ but not for the placebo group $(t=1 \cdot 58, \cdot d f=10)$. Similarly, an analysis of variance encompassing during and after active treatment showed a significant difference of response over time $(\mathrm{F}=2.74, \mathrm{df}=4, \mathrm{p}<0.035)$ with a significant drug $\times$ time of assessment interaction effect $(F=3 \cdot 67, \mathrm{df}=$ $4, p<0.009)$, which further highlights the increase in Hamilton rating scale scores for the diazepam group alone during the withdrawal period.

\section{KELLNER AND SHEFFIELD SELF RATING SCALE OF DISTRESS}

Within group $t$ tests comparing initial Kellner and Sheffield scores before entry to the study $($ day -7$)$ and before active treatment (day 0 ) failed to show any significant reduction for either the diazepam $(t=1 \cdot 12, \mathrm{df}=9)$ or placebo $(t=0.01, \mathrm{df}=10)$ groups during this single blind wash in period.

Within group $t$ tests comparing Kellner and Sheffield scores before and during active treatment showed a reduction in self reported distress for the diazepam group $(t=2 \cdot 28, \mathrm{df}=9, \mathrm{p}<0.05)$ but not the placebo group $(t=1 \cdot 57, \mathrm{df}=10)$. The trend, however, for both groups was in a similar direction, as shown by an analysis of variance for the same 
period, which failed to find any drug or drug $\times$ time of assessment interaction effect but did show a significant reduction in Kellner and Sheffield scores over assessment periods $(F=3.78, d f=4, p<0.007)$.

A comparison of the Kellner and Sheffield score during and after active treatment failed to produce any significant results. A similar trend was seen, however, for the increase in Kellner and Sheffield scores for the diazepam group $(t=1 \cdot 88, \mathrm{df}=9)$ but not for the placebo group $(t=0 \cdot 81, \mathrm{df}=10)$ during the withdrawal period.

\section{WITHDRAWAL}

Adverse withdrawal reactions at the end of the two week placebo withdrawal period (day 56) were considered to have occurred (table II) if $(a)$ there were qualitatively different symptoms from those reported at the end of the double blind active treatment period, or $(b)$ new symptoms had emerged that had not been previously reported. The diazepam group reported a significantly greater number of both types of withdrawal symptoms for each patient $(t=8.91, \mathrm{df}=19, \mathrm{p}<0.001$; $t=3.69, \mathrm{df}=19, \mathrm{p}<0.01)$ than the placebo group.

TABLE II-Adverse withdrazval reactions and numbers of patients

\begin{tabular}{|c|c|c|c|}
\hline Symptoms & $\begin{array}{l}\text { Occurred } \\
\text { previously }\end{array}$ & New symptoms & Total \\
\hline $\begin{array}{l}\text { Anxiety } \\
\text { Restlessness } \\
\text { Difficulty getting to sleep } \\
\text { Disturbed sleep } \\
\text { Apprehension } \\
\text { Dizziness } \\
\text { Nausea } \\
\text { Headaches } \\
\text { Lack of energy } \\
\text { Tremor } \\
\text { Excessive perspiration } \\
\text { Abdominal cramps } \\
\text { Faintness } \\
\text { Chest pains } \\
\text { Loss of appetite } \\
\text { Derealisation }\end{array}$ & $\begin{array}{l}8 \\
3 \\
4 \\
6 \\
2 \\
1 \\
1 \\
1 \\
2\end{array}$ & $\begin{array}{c}\text { Diazepam }(n=10) \\
4 \\
2 \\
3 \\
4 \\
3 \\
3 \\
1 \\
2 \\
2 \\
1 \\
1\end{array}$ & $\begin{array}{l}8 \\
7 \\
6 \\
6 \\
5 \\
5 \\
4 \\
3 \\
2 \\
2 \\
2 \\
2 \\
1 \\
1 \\
1 \\
1\end{array}$ \\
\hline Total & 30 & 26 & 56 \\
\hline $\begin{array}{l}\text { Anxiety } \\
\text { Constipation }\end{array}$ & 1 & $\begin{array}{c}\text { Placebo }(n=11) \\
1\end{array}$ & $\begin{array}{l}1 \\
1\end{array}$ \\
\hline Total & 1 & 1 & 2 \\
\hline
\end{tabular}

\section{Discussion}

Patients who had taken diazepam and to a less extent those who had taken placebo reported a significant reduction in anxiety ratings as assessed by Hamilton rating scale scores. Both drugs were most effective during the first week of active double blind treatment, a result similar to that found by Shapiro et al. ${ }^{\circ}$ The effectiveness of both drugs as assessed by Kellner and Sheffield self reports was less noticeable, although the trend was similar in direction.

No significant reduction in Kellner and Sheffield scores was seen in either group during the initial placebo wash in period. The reduction in anxiety ratings during the first week of double blind treatment may have been partly due to other factors apart from the drug - for example, the introduction of the psychologist assessor, whose sole concern was assessment of efficacy and who purposely did not provide any direct treatment but, nevertheless, provided a certain degree of increased contact with the patient. This suggests that non-specific factors such as amount of contact with patients during drug trials may play a substantial part in determining the outcome of treatment.

A number of problems exist in defining withdrawal symptoms after the end of anxiolytic treatment. Owen and Tyrer suggested that the first symptoms experienced during withdrawal are similar to those of anxiety, and one may therefore assume that they have previously occurred during or before treatment. ${ }^{24}$ Whether these symptoms are a recurrence of clinical anxiety or a drug withdrawal reaction is difficult to determine. The emergence of new symptoms during withdrawal is, however, less likely to be due to rebound anxiety. Owen and Tyrer also stated that the presentation of new symptoms and a temporary increase in preexisting symptoms can indicate a withdrawal syndrome. ${ }^{24}$

Our results suggest that withdrawal from diazepam by substitution with single blind placebo leads to an increase in both rebound and withdrawal symptoms after a short period of treatment. Although gradual withdrawal would have probably reduced the number of symptoms, ${ }^{24}$ the single blind withdrawal treatment with placebo showed that the symptoms reported were not false reactions that had occurred due to the end of tablet consumption but were specifically due to the end of diazepam treatment.

Our finding that withdrawal symptoms can occur, albeit without graded withdrawal, after a relatively short period of treatment has important implications for management. The present trend has been the advocacy of reduced duration of treatment. ${ }^{5}$ The minimum length of regular treatment before dependence can occur is regarded by some as three months. ${ }^{25}$ Our study suggests that withdrawal symptoms occur at normal therapeutic doses and when diazepam is used for what has hitherto been regarded as a safe length of treatment.

We suggest that a reassessment of the use of benzodiazepine is required. Rickels has proposed that many acutely anxious patients require treatment with drugs for only a few days or weeks. ${ }^{25}$ Patients with chronic or suvere conditions may also benefit from short term intermittent treatment with graded withdrawal, thereby enhancing the effectiveness of treatment and minimising the risk of dependency.

This work was supported by Astra Pharmaceuticals and approved by the Forth Valley Health Board local district ethical committee.

We thank all general practitioners of the Forth Valley general practitioner research group, including Drs Bidwell, Brown, Fairley, Fisher, Loudon, McKinnon, Mullen, Munn, Rodger, and Walker and research assistant S A Milne. We also thank Dr R R MacDonald for help with computing and V Swanson for the typescript.

\section{References}

1 Institute for the Study of Drug Dependence. Drug abuse briefing. London: Redesign 1982 .

Skegg DCG, Doll R, Perry J. Use of medicines in general practice. Br Med $\mathcal{f}$ 1977;i:1561-3.

3 Shepherd M, Cooper B, Brown AC, Kalton G. Psychiatric illness in general practice. London: Oxford University Press, 1966

4 Greenblatt DJ, Shader RJ. Benzodiazepines in clinical practice. New York: Raven

5 Committee on the Review of Medicines. Systematic review of the benzodiazepines. $\mathrm{Br}$ Med f 1980

Shapiro AK, Struening EL, Shapiro E, Milcarek BI. Diazepam-how much better than placebo ? Fsychiatr Res $1983 ; 17: 51-73$

8 Pesce A, Rossi F, Valeri P. Side effects of benzodiazepines "rebound" anxiety and insomnia. Clin Ther 1981;99:461-70.

9 Hallstrom C, Lader M. Benzodiazepine withdrawal phenomena. Int Pharmacopsychiatry 1981;16:235-44.

10 Lader M. Benzodiazepine withdrawal states. In: Trimble MR, ed. Benzodiazepines divided. New York: John Wiley and Sons, 1983.

11 Ashton H. Benzodiazepine withdrawal: an unfinished story. Br Med f 1984 ;288: $1135-40$

12 Tyrer $P$, Owen $R$. Anxiety in primary care: is short term drug treatment appropriate ? f Psychiatr Res 1984;18:73-8.

13 Preskorn $\mathrm{H}$, Denner J. Benzodiazepines and withdrawal psychosis: report of three cases. $7 A M A$ 1977;237:36-8.

14 Miller F, Neilson J. Diazepam (Valium) detoxification. F Nerv Ment Dis 1979; 167:637-8.

15 De Bard ML. Diazepam withdrawal syndrome: a case of psychosis, seizures and coma. Am f Psychiatry 1979;136:105-6.

16 Peturson $\mathrm{H}$, Lader $M H$. Withdrawal from long term benzodiazepine treatment. Br Med f 1981;283:643-54.

17 Fontaine $\mathrm{R}$, Chouinard G, Annable L. Rebound anxiety in anxious patients: abrupt withdrawal of benzodiazepine treatment. Am f Psychiztry 1984;141 :

18 Winokur A, Rickels K, Greenblatt DJ, Snyder PJ, Schatz NJ. Withdrawal reacion from long term low dosage administration of diazepam. Arch Gen Psychiatry $1980 ; 37: 101-5$

19 Wing JK, Cooper JE, Sartorius N. Present state examination. Cambridge: Cambridge University Press, 1973.

20 Spitzer RL, Endicott J, Robins E. Research diagnostic criteria. New York: New York State Psychiatric Institute, 1978.

21 Hamilton $M$. The assessment of anxiety states by rating. $\mathrm{Br} \mathcal{F}$ Med Psychol $1959 ; 32: 50-5$

22 Kellner R, Sheffield BF. A self-rating scale of distress. Psychol Med 1973;3:

23 Howel DC. Statistical methods for psychology. Boston: Duxbury Press, 1982. 24 Owen RT, Tyrer P. Benzodiazepine dependence: a review of the evidence. Drugs

25 Rickels K. Benzodiazepines: clinical use patterns. In: Sarza SI, Ludford JP, eds. Benzodiazepines: a review of research results. Washington: United States of America Government Printing Office, 1980.

(Accepted 6 February 1985) 